\title{
Effect of Carvacrol on Salmonella Saintpaul Biofilms on Stainless Steel Surface
}

\author{
Nancy Sayuri Uchida ${ }^{1}$, Renata Grespan ${ }^{2}$, Michelle Piovezan $^{1}$, Erika C Ferreira ${ }^{1}$, \\ Miguel Machinski Júnior ${ }^{3}$, Roberto Kenji Nakamura Cuman ${ }^{2}$ and Jane Martha G \\ Mikcha $^{1 *}$ \\ ${ }^{1}$ Graduate Program in Health Sciences, Department of Clinical Analysis and Biomedicine, ${ }^{2}$ Graduate Program in Health \\ Sciences, Department of Pharmacology and Therapeutics, ${ }^{3}$ Graduate Program in Health Sciences, Department of Basic Health \\ Sciences, State University of Maringá, Maringá, Brazil
}

*For correspondence: Email: jmgmikcha@uem.br; Tel: +55 (44) 3011-4813; Fax: + 55 (44) $3011-4959$

Received: 19 December 2013

Revised accepted: 12 November 2014

\begin{abstract}
Purpose: To evaluate the effect of carvacrol against Salmonella saintpaul biofilms on stainless steel surface.

Methods: The effect of carvacrol on planktonic cells of $S$ saintpaul was evaluated by determining the minimum inhibitory concentration (MIC) and minimal bactericidal concentration (MBC). The action of carvacrol on S. saintpaul biofilms on stainless steel surface was evaluated on established biofilm and on biofilm formation by counting the number of bacterial cells that adhered to the surface and by scanning electron microscopy.

Results: The antimicrobial activity of carvacrol against planktonic cells of S. saintpaul was observed. The highest inhibitory effect of carvacrol was observed during biofilm formation at 78 and $117 \mu \mathrm{g} \mathrm{m} \Gamma^{1}$ when S. saintpaul biofilms were reduced by 3 log cycles $(p<0.05)$.

Conclusion: Carvacrol reduced the number of bacterial cells that adhered to stainless steel surface, making it a potential compound for Salmonella saintpaul control.
\end{abstract}

Keywords: Salmonella spp., Biofilm, Carvacrol, Antimicrobial activity, Planktonic cells, Stainless steel

Tropical Journal of Pharmaceutical Research is indexed by Science Citation Index (SciSearch), Scopus, International Pharmaceutical Abstract, Chemical Abstracts, Embase, Index Copernicus, EBSCO, African Index Medicus, JournalSeek, Journal Citation Reports/Science Edition, Directory of Open Access Journals (DOAJ), African Journal Online, Bioline International, Open-J-Gate and Pharmacy Abstracts

\section{INTRODUCTION}

Salmonella infection constitutes a major public health problem in many countries and millions of cases of salmonellosis are reported worldwide [1]. The ability of Salmonella spp. to adhere and form biofilm is an important contributory factor to its resistance and persistence in different environments, especially in the food processing industry. The surfaces of stainless steel equipment and utensils are known to be major sites of bacterial adhesion and biofilm formation and can consequently lead to food deterioration or food-borne disease transmission [2].
Several strategies for controlling bacterial adhesion to surfaces have been proposed, including the use of natural compounds. Many studies have demonstrated the action of essential oils in the adhesion of bacteria on different surfaces [2-4].

Carvacrol is an important component of the essential oils of oregano and thyme and is considered a broad-spectrum antimicrobial compound [5]. Although the antimicrobial effect of carvacrol is well documented, few studies have evaluated its effects on bacterial biofilms 
$[6,7,8]$. The effects of carvacrol on Salmonella spp. biofilms were evaluated by Knowles and Roller [9] and by Knowles et al [10] on Salmonella typhimurium NCTC 74 biofilms on stainless steel.

In this context, the objective of the present study was to evaluate the effect of carvacrol on biofilms of S. saintpaul on stainless steel surface.

\section{EXPERIMENTAL}

\section{Microorganism}

S. saintpaul used in this research was isolated from raw material used for animal feed and was stored at the Laboratory of Food Microbiology, Department of Biomedicine and Clinical Analysis, State University of Maringá.

\section{Effect of carvacrol on planktonic cells}

The minimum inhibitory concentration (MIC) of carvacrol was determined using the broth microdilution method according to M7-A8 of the Clinical Laboratory Standards Institute [11]. Carvacrol (98\% purity) was obtained from Sigma (Steinheim, Germany). The compound was diluted in ethanol and tested at final concentrations that ranged from 19 to $5000 \mu \mathrm{g}$ $\mathrm{ml}^{-1}$. The MIC was defined as the lowest concentration of carvacrol that inhibited bacterial growth. Two bacterial growth controls that consisted of Mueller Hinton Broth (MHB; Difco, Le Pont de Claix, France) and $0.5 \%$ ethanol $(\mathrm{v} / \mathrm{v})$ and one control that consisted of carvacrol in $\mathrm{MHB}$ were included. Ampicillin was used as a standard drug at concentrations of 0.5 to $128 \mu \mathrm{g}$ $\mathrm{ml}^{-1}$ against $E$. coli ATCC 25922. Each test was performed in duplicate and repeated three times.

\section{Stainless steel surfaces}

AISI 304 stainless steel coupons ( 1 × 8 × $9 \mathrm{~mm})$ were washed with $100 \%$ acetone by immersion, dried, and cleaned with $70 \%$ alcohol (v/v). Thereafter, they were washed with distilled water, dried for $2 \mathrm{~h}$ at $60{ }^{\circ} \mathrm{C}$ and autoclaved at $121^{\circ} \mathrm{C}$ for $15 \mathrm{~min}$.

\section{Inoculum preparation}

To biofilm formation on stainless steel, overnight cultures S. saintpaul at $35^{\circ} \mathrm{C}$ were diluted $1: 100$ in Tryptic Soy Broth (TSB; Merck, Darmstadt, Germany) to obtain approximately $10^{7} \mathrm{CFU} \mathrm{ml}^{-1}$ (colony-forming units per milliliter), confirmed by counting the CFU on Hektoen agar.

\section{Biofilm formation}

The stainless steel coupons were individually placed in sterile microtubes in triplicate that contained $1500 \mu \mathrm{l}$ of the bacterial inoculum and incubated at $35^{\circ} \mathrm{C}$ for $24 \mathrm{~h}$. After incubation, the contents were aspirated and replaced by $1500 \mu \mathrm{l}$ $\mathrm{TSB}$, and the microtubes were reincubated at 35 ${ }^{\circ} \mathrm{C}$ for $24 \mathrm{~h}$. TSB was used as the negative control, and the positive controls were $P$. aeruginosa ATCC 27853 and Klebsiella pneumoniae ATCC 700603.

\section{Effect of carvacrol on biofilm}

\section{Established biofilms}

After biofilm formation on stainless steel for $48 \mathrm{~h}$, the coupons with attached bacteria were washed with $0.85 \%$ sterile saline solution and exposed to carvacrol at concentrations of 39,78 , and $117 \mu \mathrm{g}$ $\mathrm{ml}^{-1}$, corresponding to 25,50 , and $75 \%$ of MIC, respectively, for $1 \mathrm{~h}$ at room temperature. The control, consisting of TSB and bacterial inoculum, were included in the experiment. The tests were performed in triplicate and repeated twice.

\section{Biofilm formation}

Carvacrol (39, 78 and $117 \mu \mathrm{g} \mathrm{ml}^{-1}$ ) was added to microtubes that contained the coupons and bacterial inoculum. After $24 \mathrm{~h}$, the contents of the microtubes were replaced by $1500 \mu \mathrm{TSB}$ with the same concentrations of carvacrol followed by incubation at $35{ }^{\circ} \mathrm{C}$ for $24 \mathrm{~h}$. A control of biofilm formation with the same inoculum without carvacrol was included in the assay. The tests were performed in triplicate with two independent repetitions.

\section{Counting of adhered bacterial cells}

After $48 \mathrm{~h}$ of incubation, the microtube contents were aspirated, and the control coupons without carvacrol and coupons exposed to different concentrations of carvacrol $(39,78$, and $117 \mu \mathrm{g}$ $\mathrm{ml}^{-1}$ ) were washed with $0.85 \%$ sterile saline solution, placed in the $0.85 \%$ sterile saline solution, and subjected to an ultrasonic bath at $25 \mathrm{~Hz}$ for $5 \mathrm{~min}$ (Ultra Cleaner 750A, Unique). Serial dilutions were performed in sterile saline solution, plated on MHA (Difco, Le Pont de Claix, France), and incubated at $35{ }^{\circ} \mathrm{C}$ for $24 \mathrm{~h}$. The results were expressed in log CFU $\mathrm{cm}^{-2}$.

\section{Scanning electron microscopy}

Biofilm formation on stainless steel was analyzed using scanning electron microscopy (SEM). The 
coupons were washed with $0.85 \%$ sterile saline solution, fixed with $2.5 \%$ glutaraldehyde in $0.1 \mathrm{M}$ sodium cacodylate buffer, and kept for $48 \mathrm{~h}$ under refrigeration. The coupons were washed twice in $0.1 \mathrm{M}$ sodium cacodylate buffer and dehydrated in a graded series of ethanol $(50,70$, 80 and $90 \%$ ) and twice in $100 \%$ ethanol. The coupons were subjected to critical-point-dried in $\mathrm{CO}_{2}$, coated with gold, and examined by scanning electron microscopy (Shimadzu SS550).

\section{Statistical analysis}

The statistical analysis was performed using Statistica 8.0 and 2.14.0 software. We used descriptive measures (mean and standard deviation) followed by t-test to compare differences between the control group and carvacrol-treated groups. The level of statistical significance was set at $p<0.05$.

\section{RESULTS}

\section{Effect of carvacrol on planktonic cells}

Carvacrol was able to inhibit $S$. saintpaul growth, with a MIC of $156 \mathrm{\mu g} \mathrm{ml}^{-1}$.

\section{Biofilm formation on stainless steel surface}

The number of $S$. Saintpaul cells on stainless steel was approximately $8 \log$ CFU cm$~^{-2}$ (Table $1)$. The bacterial adhesion to stainless steel was uniform (Figure 1).

\section{Effect of carvacrol on established biofilm}

The effect of carvacrol on preformed S. saintpaul biofilm on stainless steel is shown in Table 1. The greatest reduction of bacterial counts was observed with $117 \mathrm{\mu g} \mathrm{ml}^{-1}$ carvacrol (75\% of $\mathrm{MIC})$, in which we observed a decrease of approximately 3 log cycles in bacterial counts. However, this reduction was not statistically significant $(p>0.05)$ at any of the subinhibitory concentrations tested $(25,50$ and $75 \%$ of MIC) compared with control group.

\section{Effect of carvacrol on biofilm formation}

A reduction of the number of $S$. saintpaul cells on stainless steel after carvacrol treatment is shown in Table 1. A statistically significant reduction ( $p$ $<0.05)$ was observed on biofilms treated with carvacrol at concentrations of 39,78 , and $117 \mu \mathrm{g}$ $\mathrm{ml}^{-1}(25,50$ and $75 \%$ of MIC, respectively). SEM (Figure 1) revealed the effects of carvacrol on $S$. Saintpaul biofilm formation on stainless steel. The biofilm was reduced and almost absent at 75 $\%$ of the MIC $\left(117 \mu \mathrm{g} \mathrm{ml}^{-1}\right)$.

\section{DISCUSSION}

In the present study, we evaluated the effects of carvacrol on $S$. saintpaul biofilms. This compound inhibited biofilm formation on stainless steel.

Salmonella spp. biofilms on food contact surfaces are widely spread in food processing environments [2]. The use of carvacrol as an antimicrobial agent is an efficient alternative for Salmonella spp. control, however, only few studies have reported the effects of carvacrol on the adhesion of Salmonella spp. to stainless steel surfaces $[9,10]$.

The number of $S$. Saintpaul cells on stainless steel after $48 \mathrm{~h}$ was 7.61 and $8.77 \mathrm{log}$ CFU cm $\mathrm{cm}^{-2}$. These findings are consistent with studies that evaluated Salmonella spp. biofilm formation on steel, with counts that ranged from 5.26 to 8.01 CFU cm $\mathrm{cm}^{-2}$ after $8-120 \mathrm{~h}$ of incubation $[12,13]$.

Table 1: Effect of carvacrol on preformed Salmonella Saintpaul biofilm and Salmonella Saintpaul biofilm formation on stainless steel surface

\begin{tabular}{|c|c|c|c|c|}
\hline Biofilm & $\begin{array}{c}\text { Concentration of carvacrol } \\
\left.(\mu \mathrm{g} \mathrm{ml})^{*}\right)^{*}\end{array}$ & $\log C F U \mathrm{~cm}^{-2}$ & DP & $P$-value ${ }^{* *}$ \\
\hline \multirow{4}{*}{ Preformed } & 0 & 7.61 & 0.900 & Reference \\
\hline & 117 & 4.76 & 4.179 & 0.3126 \\
\hline & 78 & 6.49 & 1.732 & 0.3762 \\
\hline & 39 & 8.25 & 0.366 & 0.3182 \\
\hline \multirow{4}{*}{ Formed } & 0 & 8.77 & 0.113 & Reference \\
\hline & 117 & 5.18 & 0.233 & $0.00001^{\pi \pi \pi}$ \\
\hline & 78 & 5.35 & 0.078 & $0.00001^{* \star \star}$ \\
\hline & 39 & 7.00 & 0.620 & $0.0082^{* * *}$ \\
\hline
\end{tabular}

Tests were performed in triplicate in two different experiments; ${ }^{*} 117 \mu \mathrm{g} \mathrm{mr^{1 }}$ (75\% MIC), $78 \mu \mathrm{g} \mathrm{mr^{1 }}$

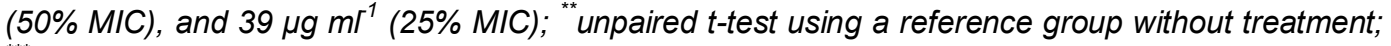
${ }^{* * *}$ difference between mean $(p<0.05)$ 


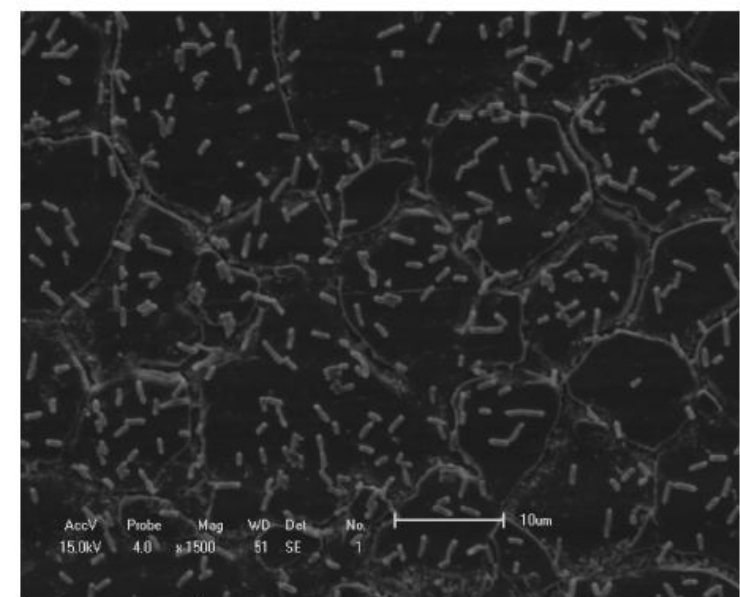

(a) Untreated

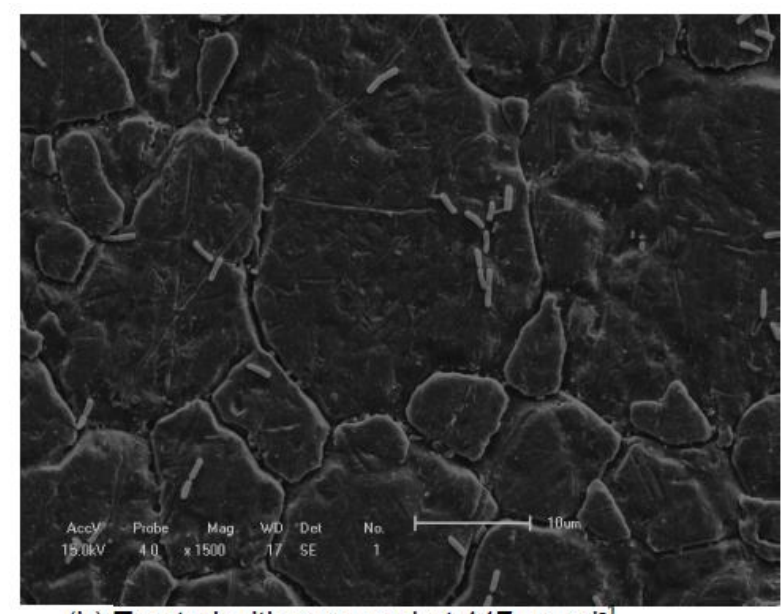

(b) Treated with carvacrol at $117 \mu \mathrm{g} \mathrm{ml}^{-1}$

Figure 1: Scanning electron microscopy images of Salmonella Saintpaul biofilm on stainless steel surface

Kim and Wei [14] showed that the initial adhesion of Salmonella spp. to steel occurred after $12 \mathrm{~h}$ of incubation, with microcolonies formation within $24 \mathrm{~h}$ and mature biofilm formed $48 \mathrm{~h}$ later. According to Wirtanen et al [4], to consider biofilms, counts above $10^{3}$ CFU $\mathrm{cm}^{-2}$ are necessary. Therefore, the results in the present study indicated the formation of biofilms on stainless steel. The results (Figure 1) showed that bacterial adhesion was uniform on the stainless steel, in which the bacteria were individualized without the presence of aggregated bacteria or an extracellular matrix. Kim and Wei [14] found the formation of microcolonies on the steel surface using SEM when Salmonella spp. was grown on turkey and beef broths, but when grown on lettuce broth, adhesion was similar to the present study. In fact, according to Steenackers et al [2], the extracellular matrix components of Salmonella biofilms vary considerably with environmental conditions, which may explain this result.

In the established biofilm, carvacrol had few effects, the largest of which occurred after treatment with $117 \mathrm{\mu g} \mathrm{ml}^{-1}$ (75\% MIC), but this reduction was not statistically significant compared with the biofilm control (Table 1). Moreover, the biofilm formation results showed that the treatment with the three concentrations of carvacrol resulted in a significant reduction of the number of cells that adhered compared with controls (Table 1 ).

These results may be attributable to the characteristics of biofilm formation that occur in two phases. During the initial phase, adhesion is reversible, and the bacteria are easily removed by the application of minimal force. In a subsequent phase, the removal of irreversibly adhered cells is difficult in mature biofilm, requiring the application of strong mechanical forces or chemical interruption of the adherence by applying enzymes, detergents, surfactants, disinfectants, or heat [15].

Similar results were observed by Knowles and Roller [9], in which the lowest concentration of carvacrol $\left(0.5 \mathrm{mmol} \mathrm{I}^{-1}\right)$ had no effect on biofilms formed by $S$. typhimurium, but the highest concentration $\left(2.0 \mathrm{mmol} \mathrm{I}^{-1}\right)$ resulted in a $2.6 \mathrm{log}$ $\mathrm{CFU} /$ surface reduction, indicating the concentration-response effects of carvacrol.

According to Knowles et al [10], during the initial phase of biofilm development ( $24 \mathrm{~h}$ ), the number of viable $S$. typhimurium was reduced by $3 \mathrm{log}$ $\mathrm{CFU} / \mathrm{biofilm}$ when treated with $1 \mathrm{mmol}$ carvacrol per hour. However, a rapid recovery of viable cell numbers was observed that exceeded and eventually equaled the cell numbers on the biofilm without treatment. In mature biofilm, after 12 days of formation, carvacrol $\left(1 \mathrm{mmol} \mathrm{I} \mathrm{I}^{-1} / \mathrm{h}\right)$ also caused a 3 log CFU/biofilm reduction after the initial exposure and an average 1 log reduction during subsequent pulses.

Nostro et al [6] also observed significant differences in $S$. aureus and $S$. epidermidis biofilm formation when treated with different concentrations of carvacrol. The concentration of $78 \mu \mathrm{g} \mathrm{ml}^{-1}$ produced a greater reduction in the number of bacterial cells that adhered to the microplate. The authors used SEM and found that the amount of biofilm was reduced in the presence of $39 \mathrm{\mu g} \mathrm{ml}^{-1}$ carvacrol and was almost absent at $78 \mu \mathrm{g} \mathrm{ml}^{-1}$.

Interesting findings were also reported by PerezConesa et al [7] who assessed the effects of encapsulated carvacrol on the inactivation of $L$. monocytogenes and E. coli O157:H7 biofilms on stainless steel. The morphological evaluation of biofilm revealed an increasing number of dead 
cells when the biofilms were treated with sufficiently high concentrations of carvacrol and a reduction of bacterial counts.

\section{CONCLUSION}

The present study demonstrates that carvacrol reduces the number of bacterial cells that adheres to stainless steel surface, thus indicating that this compound may be an alternative for Salmonella spp. control. The action of carvacrol together with other natural compounds increases its effectiveness against bacterial biofilm and may even replace the use of chemicals to disinfect surfaces during food production.

\section{ACKNOWLEDGEMENT}

This work was supported by grants from the Coordenação de Aperfeiçoamento de Pessoal de Nível Superior (CAPES) and Complexo de Central de Apoio a Pesquisa (COMCAP) of the State University of Maringá (UEM). We are grateful to Aparecida Donizeti Bidoia for technical assistance.

\section{REFERENCES}

1. World Health Organization. Drug-resistant Salmonella. [cited 2011 Nov 21]. Available from:http://www.who. int/mediacentre/factsheets/fs139/en/.

2. Steenackers $H$, Hermans $K$, Vanderleyden J, De Keersmaecker SCJ. Salmonella biofilms: an overview on occurrence, structure, regulation and eradication. J Food Research Int 2012; 45: 502-531.

3. Budzyñska A, Wiêckowska-Szakiel M, Sadowska B, Kalemba D, Rózalska B. Antibiofilm activity of selected plant essential oils and their major components. Polish J Microbiol 2011; 60: 35-41.

4. Wirtanen G, H Husmark U, Mattila-Sandholm T. Microbial evaluation of the biotransfer potencial from surfaces with Bacillus biofilms after rinsing and cleaning procedures in closed food processing systems. J Food Prot 1996; 59: 727-733.

5. Burt S. Essential oils: their antibacterial properties and potential application in foods: a review. Int J Food Microbiol 2004; 94: 223-253.
6. Nostro A, Sudano Roccaro A, Bisignano G, Marino A, Cannatelli MA, Pizzimenti FC, Cioni PL, Procopio F, Blanco AR. Effects of oregano, carvacrol and thymol on Staphylococcus aureus and Staphylococcus epidermidis biofilms. J Med Microbiol 2007; 56: 519523.

7. Pérez-Conesa D, Cao J, Chen L, McLandsborough L, Weiss J. Inactivation of Listeria monocytogenes and Escherichia coli 0157:H7 biofilms by micelle encapsulated eugenol and carvacrol. J Food Prot 2010; 74: 55-62.

8. lannitelli A, Grande R, Di Stefano A, Di Giulio M, Sozio P, Bessa LJ, Laserra S, Paolini C, Protasi F, Cellini L. Potential antibacterial activity of carvacrol-loaded poly(DL-lactide-co-glycolide) (PLGA) nanoparticles against microbial biofilm. Int J Mol Sci 2011; 12: 5039-5051.

9. Knowles J, Roller S. Efficacy of chitosan, carvacrol, and a hydrogen peroxide-based biocide against foodborne microorganisms in suspension and adhered to stainless steel. J Food Prot 2001; 64: 1542-1548.

10. Knowles, JR, Roller S, Murray DB, Naidu A.S. Antimicrobial action of carvacrol at different stages of dual-species biofilm development by Staphylococcus aureus and Salmonella enterica serovar Typhmurium. Appl Environ Microbiol 2055; 71:797-803.

11. Clinical Laboratory Standards Institute. Methods for Dilution Antimicrobial Susceptibility Tests for Bacteria that Grow Aerobically, approved standard M07-A8. 2009; 29: 1-88.

12. Jun W, Kim MS, Cho BK, Millner PD, Chao K, Chan DE. Microbial biofilm detection on food contact surfaces by macro-scale fluorescence imaging. I Food Engineering 2010; 99: 314-322.

13. Speranza B, Corbo MR, Sinigaglia M. Effects of nutritional and environmental conditions on Salmonella sp. biofilm formation. J Food Sci 2011; 76: M12-M16.

14. Kim SH, Wei Cl. Biofilm formation by multidrug-resistant Salmonella enterica serotype Typhimurium phage type DT 104 and other pathogens. J Food Prot 2007; 70: $22-29$

15. Chmielewski RAN, Frank J. Biofilm formation and control in food processing facilities. Int $J$ Food Sci Technol 2003; 2: 22-32. 